\title{
Post intubation high airway pressure's: An uncommon case of kinked tube
}

\author{
Karen Ruby Lionel ${ }^{1}$, Ajay Prasad Hrishi ${ }^{2, *}$ \\ ${ }^{\mathbf{1}}$ Associate Professor, ${ }^{\mathbf{2}}$ Assistant Professor, Dept. of Anaesthesiology, ${ }^{\mathbf{1} C h r i s t i a n ~ M e d i c a l ~ C o l l e g e, ~ V e l l o r e, ~ T a m i l ~ N a d u, ~}{ }^{2} \mathrm{Sree}$ \\ Chitra Tirunal Institute for Medical Sciences, Thiruvananthapuram, Kerala, India \\ *Corresponding Author: Ajay Prasad Hrishi \\ Email: drajay@sctimst.ac.in
}

Received: $24^{\mathrm{h}}$ May, 2018

Accepted: $6^{\text {th }}$ June, 2018

\begin{abstract}
High airway pressure's post intubation is a critical event which requires the urgent intervention of the attending anesthesiologist. We report a case of high peak pressure and plateau pressure after intubation which was actually due to the kinked scavenging tubing of anesthesia workstation. Many a times this may happen, but is missed by even the experienced anesthesiologist who attribute the high airway pressures to change in the lung compliance of the patient or faulty equipment and will immediately respond with therapeutic intervention or replace the workstation/ventilator. A systematic evaluation of the lungs as well as the function of the ventilator along with the scavenging tubing's, a commonly missed entity is mandatory in each case.
\end{abstract}

Keywords: Airway pressure, Anesthesia, Scavenging system.

\section{Introduction}

High airway pressure's post intubation is a critical event which requires the urgent intervention of the attending anesthesiologist. We report a case of high peak pressure and plateau pressure after intubation which was actually due to the kinked scavenging tubing of anesthesia workstation.

\section{Case Report}

A 50-year-old lady was scheduled for neurosurgery in the supine position. On the day of surgery she was wheeled into the operating room and standard pre induction monitors consisting of electrocardiogram (ECG), pulse oximetry $\left(\mathrm{Spo}_{2}\right)$, non invasive blood pressure (NIBP) anesthetic was attached. Anesthesia was induced with Inj. Thiopentone 5 mcg. $\mathrm{kg}^{-1}$, Inj. Fentanyl 2 mcg. $\mathrm{kg}^{-1}$ and after confirming ventilation muscle relaxation was achieved with Inj. Vecuronium 0.1 mg.kg ${ }^{-1}$. Trachea was cannulated with 7.0 reinforced endotracheal tube and was mechanically ventilated in volume control mode of ventilation (VCV) targeting a tidal volume of $8 \mathrm{ml} / \mathrm{kg}$ with a respiratory rate of 12 breaths/min and peak end expiratory pressure (PEEP) of 5. Post intubation the peak airway pressure $\left(\mathrm{P}_{\text {peak }}\right)$ was 13 $\mathrm{cm} \mathrm{H}_{2} \mathrm{O}$ and Plateau pressure ( $\mathrm{P}_{\text {plat }}$ ) of $7 \mathrm{~cm} \mathrm{H}_{2} \mathrm{O}$. After the patient was positioned for surgery the ventilator alarms were triggered showing high airway peak pressure $\left(>30 \mathrm{~cm} \mathrm{H}_{2} \mathrm{O}\right)$ along with high plateau pressure (>25 $\mathrm{cm} \mathrm{H}_{2} \mathrm{O}$ ).

Auscultation revealed bilateral equal air entry in all lung fields without any added sounds, expiratory and inspiratory tidal volumes were equal and patient was hemodynamically stable. The end tidal carbon dioxide trace $\left(\mathrm{EtCo}_{2}\right)$ was showing normal square wave pattern. There was no history of any lung pathologies or a reactive airway disease. The ventilator circuits and endotracheal tube were checked for any kinks or block and the check of the machine showed that the inspiratory and expiratory valves were functioning normally. We reduced the tidal volume to match $6 \mathrm{ml} / \mathrm{kg}$ despite which the airway pressures continued to rise after each sequential breath. We switched the patient from mechanical ventilation to bag ventilation and noticed that even with the Adjustable Pressure Limiting (APL) value fully open there was high resistance for ventilation. This prompted us to ventilate the patient switch on AMBU bag and as soon as the patient was taken over on the AMBU bag there was no more resistance to ventilation. We further evaluated the ventilator and the expiratory valve which were found to be functioning well and hence it was decided to replace the anesthesia workstation. At that point, it was noted that the gas scavenging tube from the exhaust port of the ventilator situated behind the workstation was trapped under the wheel of the workstation. After liberating the gas scavenging tube, the patient was reconnected to the ventilator and the airway pressures were found within normal limits.

\section{Discussion}

The high airway pressure alarm in the intraoperative setting is considered as an anesthetic emergency. An increased peak pressure with normal plateau pressures signifies an extra pulmonary cause, commonly a kink or block in the endotracheal tube or circuit tubing. Whereas increased peak pressures along with an increase in the plateau pressure signifies a change in the lung compliance which could be attributed to bronchospasm, endotracheal intubation, pneumothorax, pulmonary edema or any interstitial /parenchymal lung disorder. ${ }^{1,2}$ Other scenarios which may mimic this clinical picture is a faulty expiratory value of the ventilator in the anesthesia workstation. ${ }^{3}$ In our patient a systematic evaluation of the history and clinical evaluation of the 
respiratory system revealed no abnormalities. This prompted us to check for equipment related problems. The obstruction of the breathing circuit system due to kinking of the disposable as well as silicone tubing's has been documented previously as cause for sudden high intraoperative airway pressures. ${ }^{4}$ Also the obstructed ventilator breathing circuits mimicking bronchospasm have also been reported. ${ }^{3}$ We checked the hoses of breathing circuit before the induction of the case as well as after the onset of the onset of the and did not find any abnormality. Similarly the endotracheal tubes were also properly secured without any kinks and suctioning of the endotracheal tube revealed no blockade of the tube. The other commonly overlooked problem being a faulty expiratory valve prompted us to check the valves which was functioning normally.

We were intrigued by the fact that why the peak airway pressure and plateau pressure should increase to such high level and also concerned that such high airway pressure can lead to barotrauma. The absence in resistance to ventilation with an AMBU bag ruled out any patient factors contributing to this phenomenon. This prompted us to recheck the workstation which lead to the discovery of the kinked ventilator scavenging tubing's. This must have possibly occurred during the mobilization of the anesthesia during the rearrangement the operating room layout post patient positioning. Kinked scavenging tubes obstruct the outflow of the expiratory gases which in turn contribute to back pressure to system which in turn lead to the high airway pressures. This mimics a poor lung compliance scenario as both $\mathrm{P}_{\text {peak }}$ and $\mathrm{P}_{\mathrm{Plat}}$ is increased. Kinked exhaust scavenging tubing resulting in increased peak and plateau pressures has not been reported till date as evidenced by our review of published literature. Kinked scavenging tubes are often overlooked by the attending anesthesiologists as they are at the back of the machine and is often neglected. More importantly many a times this may happen, this is missed by even the experienced anesthesiologist who attribute the high airway pressures to change in the lung compliance of the patient or faulty equipment and will immediately respond with therapeutic intervention or replace the workstation/ventilator. Routine inspection of scavenging tubes should be a part of mandatory machine check prior to administration of general anesthetics as well as after repositioning of the machine.

\section{Conclusion}

Modern anesthesia ventilators come with multiple safety features to make our anesthesia practice anesthesia safer and easier. Airway pressure monitoring is very important in modern day anesthesia practice. A systematic evaluation of the lungs as well as the function of the ventilator along with the scavenging tubing's, a commonly missed entity is mandatory in each case.
Funding: No Funding

\section{References}

1. Vinay, B., Sriganesh, K., Gopalakrishna, K. N., \& Sudhir, V. An unusual cause of high peak airway pressure: Interpretation of displayed alarms. Saudi $J$ of Anaesth, 2015;9(1), 94-96.

2. The Australian Incident Monitoring Study. Crisis management - Validation of an algorithm by analysis of 2000 incident reports. Anaesth Intensive Care. 1993;21:579-92.

3. Dorsch JA, Dorsch SE, editors. 5th ed. Philadelphia, USA: Lippincott Williams \& Wilkins; 2008. Understanding Anesthesia Equipment; pp. 334-9.

4. Desai S, Torgal S, Rao R. Breathing circuit obstruction caused by kink in the reinforced kink-resistant circle system tube. Indian J Anaesth. 2013;57:96-7.

How to cite this article: Lionel K R, Hrishi A P. Post intubation high airway pressure's: An uncommon case of kinked tube. Indian J Clin Anaesth. 2018;5(4):625-626. 